\title{
Intrauterine balloon tamponade in the management of atonic postpartum haemorrhage: case study from a tertiary care hospital
}

\author{
Rupali A Gaikwad, Shrinivas N Gadappa
}

\author{
Corresponding author: Dr. Rupali A Gaikwad, Assistant Professor, Department of Obstetrics and \\ Gynecology, Government Medical College, Aurangabad, Maharashtra, India; Email : \\ drrupaligaikwad@gmail.com
}

Distributed under Attribution-Non Commercial - Share Alike 4.0 International (CC BY-NC-SA 4.0)

\begin{abstract}
Objective: Objective of the study was to study the efficacy of condom tamponade to arrest bleeding in cases of atonic postpartum haemorrhage ( $\mathrm{PPH})$ unresponsive to uterotonics. Methods: We conducted prospective observational study, in the Department of Obstetrics and Gynecology of Govt. Medical college \& hospital, Aurangabad for 2 yrs. UBT (uterine balloon tamponade) was applied to women who developed atonic PPH following childbirth unresponsive to uterotonics. UBT was inflated with normal saline. Clinical success was defined as control of bleeding following balloon insertion without further intervention. Results: Out of the 385 women who had atonic PPH, 63 were managed with insertion of condom balloon catheter after failed medical management. Success rate was 61 out of 63 cases $(96.8 \%)$. In 3 cases bleeding persisted even after 30 minutes and surgical intervention done for 2 of the 3 cases; in the third patient bleeding was arrested 30 minutes after tamponade application (1.63\%). In $9(14.2 \%)$ patients UBT was expelled spontaneously within 6 hours, out of it 2 required further surgical intervention due to uncontrolled PPH. In 93.6\% cases bleeding got controlled within 15-30 mins of condom tamponade insertion, the balloon was inflated for an average of 18 hours before removal. Conclusions: Condom catheter is a noninvasive, effective, conservative method of PPH management. In cases of failure it provides a temporary tamponade effect and time to prepare for other interventions.
\end{abstract}

Obstetric haemorrhage is a major contributor to worldwide maternal morbidity and mortality. ${ }^{1}$ The overall prevalence of PPH worldwide is estimated to be 6 to 11 percent. ${ }^{2}$ Even with standard management, approximately $3 \%$ of vaginal deliveries result in postpartum hemorrhage. PPH can kill rapidly if not managed in time. Death from postpartum haemorrhage is avoidable by timely detection and management. According to the World health organization, obstetrics haemorrhage causes 127,000 deaths
Keywords: Uterine balloon tamponade, atonic PPH.

annually worldwide and is the leading cause of maternal mortality. Uterine atony is responsible for $80 \%$ of primary $\mathrm{PPH}$. The rest are attributed to retained placental tissues, uterine rupture, lower genital tract trauma, consumptive coagulopathy etc. ${ }^{3}$ Reported incidence of PPH in India is $2 \%$ - $4 \%$ after vaginal delivery and $6 \%$ after caesarean section with uterine atony being the most common cause (50\%). ${ }^{4}$

Presently uterine balloon tamponade (UBT) is being advocated by various guidelines for the management PPH

Received: $2^{\text {nd }}$ July 2020, Peer review completed: $25^{\text {th }}$ July 2020, Accepted: $29^{\text {th }}$ July 2020.

Gaikwad RA, Gadappa SN. Intrauterine balloon tamponade in the management of atonic postpartum haemorrhage: case study from a tertiary care hospital. The New Indian Journal of OBGYN. 2021; 7(2): 148-52. 
after the exclusion of retained products and genital tract trauma. Uterine balloon tamponade has been included as second line treatment for PPH secondary to uterine atony. In these situations, the balloon is usually used as a form of treatment following the failed use of first line uterotonics such as oxytocin, ergometrine, misoprostol and prostaglandin F2 alpha. In studies successful balloon tamponade outcomes have been reported in the range of 80 $100 \%{ }^{5,6}$ We report 63 cases of atonic PPH with failed medical treatment which were managed successfully with uterine balloon tamponade. The aim was to add to the existing knowledge of uterine balloon tamponade and also to recommend the training of all skilled birth attendants on how to insert the uterine balloon tamponade catheter for uterine tamponade. And to evaluate the effectiveness of condom catheter balloon tamponade in atonic PPH management to prevent hysterectomy and to report our experience of its use.

\section{Materials and methods}

This study was a prospective observational study done in the Department of Obstetrics and Gynaecology, Government Medical College \& hospital Aurangabad, Maharashtra. It gets referral from all over Marathwada region of Maharashtra with delivery rate of about 18,000 deliveries per year. After approval from the Institutional Ethics Committee, prospective data of all women who delivered from $1^{\text {st }}$ January 2017 to $31^{\text {st }}$ December 2018 in the department was obtained. Data analysed including age, parity, onset of labour, delivery details, need of blood and blood products transfusion, vitals of patient during UBT insertion and final outcome including need for additional procedures and associated complications.

Inclusion criteria: Women with atonic PPH where uterotonics failed to respond and managed with uterine balloon tamponade.

Exclusion criteria: Traumatic PPH and cases where surgery was mandatory as retained placental tissues, invasive moles, morbid adhesions of placenta etc. PPH due to coagulation defect and women with secondary PPH were also excluded.

Primary postpartum hemorrhage was defined as the loss of more than $500 \mathrm{ml}$ of blood within the first 24 hours of delivery or loss of any amount that is enough to cause hemodynamic instability in the mother or loss of more than $10 \%$ of the total blood volume. Diagnosis is confirmed to be atonic PPH after excluding uterine and cervical trauma, deficient coagulation or retained placental tissue. A stepwise approach in the management of PPH was followed according to the departmental slandered operative protocol. Initial management of atonic PPH was implemented immediately upon diagnosis, which included resuscitative measures, correction of hypovolemia, using suitable uterotonics, uterine massage and/or bimanual compression. All these measures were tried before the cases were termed intractable to these measures. Thus, in these cases, uterine balloon tamponade was applied. In the majority of cases the decision for balloon insertion was made on the basis of active and continuous bleeding inspite of conservative measures. Sometimes in high risk women balloon insertion was carried out as a prophylactic measure by anticipating potential $\mathrm{PPH}$.

For PPH following vaginal delivery, the condom Foley's was prepared by applying condom on Foley's catheter and tying with thread and then inserted transvaginally (using sponge holding forceps or manually into uterine cavity). If UBT required during a CS, the catheter was either inserted through the uterine incision (pushing the tip towards fundus and the distal end of the balloon shaft through the cervix with an assistant pulling vaginally) or transvaginally and inflated after the uterus was closed. After insertion, the cervical balloon was inflated with $15 \mathrm{ml}$ normal saline to avoid slippage from the open os, then condom balloon inflation with $20 / 60 \mathrm{ml}$ syringe until resistance was felt or bleeding was controlled - usually from $50-300 \mathrm{ml}$ in our study. In cases of atonic PPH, to keep the uterus well contracted over the balloon, oxytocin infusion was continued for a minimum of 2 hours. In all cases, as a rule the urinary catheter was left in situ for the duration of balloon tamponade in all and the patients' vitals were closely monitored. Clinical success was defined as control of bleeding following balloon insertion without further intervention.

During the procedure, a surgical team was kept stand-by ready for surgical intervention (laparotomy and other necessary measures). If the bleeding did not stop within half an hour of tamponade application, the method was termed unsuccessful and women posted for surgical intervention. Throughout the procedure, adequate antibiotic coverage was maintained along with oxytocin drip and the condition of the patient monitored.

Data was analysed with Microsoft Excel 2007. To interpret the data, descriptive statistics like mean and percentages were used.

\section{Results}

Total numbers of deliveries in the above period were 36010. A total of 538 patients had PPH, the incidence of 
The New Indian Journal of OBGYN. 2021 (January-June);7(2)

PPH being $1.4 \%$. Out of these cases 385 had atonic PPH, $259(67.2 \%)$ managed with uterotonics, 63 (16.3\%) required UBT insertion for managing PPH (Table 1).

\begin{tabular}{ll} 
Table 1: Number of cases of PPH & Number \\
\hline Categories & 36010 \\
\hline No of deliveries & 538 \\
No of PPH cases & 385 \\
No of atonic PPH & 259 \\
No of atonic PPH managed with uterotonics & 63 \\
No of atonic PPH managed with UBT & 63 \\
No of patients required surgical procedures like B - lynch and & \\
\hline other brace sutures, systematic devascularization of uterus. & 63 \\
\hline PPH - Postpartum haemorrhage, UTB - Uterine balloon tamponade \\
\hline
\end{tabular}

Out of the 385 patients of atonic PPH, 259 patients were managed with uterotonics and bleeding was controlled. 63 patients required additional surgical procedures like B-lynch and other brace sutures, systematic devascularisation of uterus. Obstetric hysterectomy was done directly in 7 patients as their condition demanded it and 63 were managed with insertion of condom catheter.

Table 2: The risk factors for atonic postpartum haemorrhage ( $N=385$ )

\begin{tabular}{ll}
\hline Risk factors & Number \\
\hline Multiparity & 81 \\
Antepartum haemorrhage & 56 \\
Anemia & 35 \\
Multiple pregnancy & 26 \\
Prolonged labour & 19 \\
Large for gestational age & 13 \\
Polyhydramnios & 8 \\
Severe preeclampsia & 43 \\
Hepatitis & 11 \\
Others & 2 \\
\hline
\end{tabular}

As discussed in table 2, most common risk factor for atonic PPH found to be multiparity 81 cases $(21 \%)$, it was more than one risk factor in many patients.

Table 3: Shows clinical characteristics of patient who underwent condom catheter

\begin{tabular}{ll}
\hline Clinical characteristics & Number $\mathbf{( N = 6 3 )}$ \\
\hline Age (years) & 11 \\
$20-25$ & 46 \\
$>25-35$ & 6 \\
$>35$ & 11 \\
Parity & 36 \\
\hline 1 & 16 \\
$2-3$ & 9 \\
$>3$ & 42 \\
Gestational age at delivery (weeks) & \\
\hline$<37$ weeks & 12 \\
$>37-40$ & 9 \\
$>40$ & 48 \\
Birth weight in grams & 6 \\
\hline$<2500$ & 59 \\
$2500-3500$ & 4 \\
$>3500$ & \\
Delivery mode & \\
\hline Vaginal & \\
LSCS & \\
\hline LSCS - Lower segment caesarian section \\
\hline
\end{tabular}

As shown in table 3, most common age group was between $25-35$ yrs i.e. 46 out of $63(73 \%)$. 36 women were with parity $2-3(57 \%)$ and 16 with parity more than $3(25.3 \%)$. 42(66.6\%) women with gestational age between 37- 40 weeks. $59(93.6 \%)$ patients delivered vaginally. $59(93.6 \%)$ patients in whom condom tamponade was applied to control PPH had normal delivery; PPH unresponsive to uterotonics following LSCS in $4(6.3 \%)$ patients of which one had tamponade insertion abdominally, in whom caesarean was done for failed trial first degree CPD; tamponade successfully controlled bleeding. Rest three patients had atonic PPH after $4 \mathrm{hrs}$ of LSCS (average); condom tamponade was inserted vaginally and bleeding controlled.

Table 4: Number of blood transfusions required and shock index

\begin{tabular}{ll}
\hline No of blood /blood components transfusions & $\mathbf{N}=\mathbf{6 3}$ \\
\hline None & 3 \\
2 & 9 \\
$>2$ & 51 \\
\hline Shock Index & \\
$0.5-0.7$ & 3 \\
$0.9-1.1$ & 49 \\
$>1.1$ & 11 \\
\hline
\end{tabular}

In 49 cases balloon insertion was therapeutic to control intractable hemorrhage. The primary cause of $\mathrm{PPH}$ in this group was atony. Balloon insertion was carried out as a prophylactic measure in 14 women in anticipation of potential PPH. All these women had identifiable risk factors for PPH (Table 3). All patients had active management of the third stage of labor, followed by use of uterotonics according to slandered protocols.

\begin{tabular}{lll}
\multicolumn{3}{l}{ Table 5: Time to arrest bleeding and time of removal of UBT } \\
\hline Time & $\mathbf{N}=\mathbf{6 3}$ & Percentage (\%) \\
\hline 15-30min & 60 & 93.6 \\
>30min & 3 & 4.9 \\
\hline Time of removal of UBT & & \\
Expelled spontaneously within 6 hours & 9 & 14.2 \\
Removed 12-18 hours & 42 & 66.6 \\
Removed >18-24 hours & 12 & 19.04 \\
\hline
\end{tabular}

Blood transfusion given for $97 \%$ cases in whom condom tamponade was put to control atonic PPH (Table 4). Shock index (SI) is used to identify patient in shock. SI is HR (heart rate) / SBP (Systolic blood pressure). The normal value is 0.5-0.7. With significant haemorrhage, it increases to 0.91.1. The change in SI of an individual patient appears to correlate better in identifying early acute blood loss than the $\mathrm{HR}$, SBP or diastolic blood pressure used in isolation. $77.7 \%$ (49) cases had PPH associated with features of shock with a shock index $>0.7$. $11(17.4 \%)$ patients were with shock index $>1.1$ (Table 4).

In $93.6 \%$ cases bleeding got controlled within $15-30$ mins of condom tamponade insertion. In 3 cases bleeding persisted even after 30 minutes and surgical intervention done for 2 of the 3 cases; in the third patient bleeding was 
arrested 30 minutes after tamponade application (1.63\%). In $9(14.2 \%)$ patients UBT was expelled spontaneously within 6 hours, out of it 2 required further surgical intervention due to uncontrolled PPH. In 42(66.6\%) cases it was removed within 12-18 hours and was successful use without further intervention (Table 5).

\section{Discussion}

Postpartum haemorrhage is an obstetric emergency and a leading cause of maternal mortality. The recommendation is a step-wise approach to management of post-partum haemorrhage from less invasive therapies like uterine massage and uterotonic drugs to more invasive ones like arterial embolization, uterine compression sutures, uterine artery ligation and ultimately hysterectomy. ${ }^{7}$ In this prospective observational study (condom tamponade in management of atonic $\mathrm{PPH}$ ) on mothers who had atonic $\mathrm{PPH}$ unresponsive to uterotonics, condom tamponade successfully controlled bleeding in $61(96.8 \%)$ of the 63 women. The condom tamponade was applied in all 63 cases of atonic PPH, including 59 cases after vaginal delivery and 4 after caesarean delivery. It successfully controlled PPH in 61 of 63 cases $(96.8 \%)$. Goldrath $\mathrm{MH}$ was the first one to describe the successful use of a Foley's catheter to tamponade acute profuse uterine bleeding in 17 of 20 patients in $1983 .^{8}$ The idea of using a condom as a balloon tamponade evaluated in Bangladesh in 2001 by Akther S et al, to fill a need and in response to the high cost of commercially available UBT devices. $^{9}$

Regarding the secondary outcomes, no cases of maternal fever were found; blood transfusion for 60 cases $(95.2 \%)$ and hysterectomy for $2(3.1 \%)$ women. Blood transfusion given for $97 \%$ cases in whom condom tamponade was put to control atonic PPH.

In present study condom tamponade effectively controlled bleeding (unresponsive to uterotonics) in $96.8 \%$ cases. Only 2 out of 63 cases had continued bleeding despite use of condom tamponade. First case bleeding continued despite condom tamponade administration (even after 30 mins of applying tamponade) and hence laparotomy and surgical intervention was done (bilateral uterine artery ligation and modified B-Lynch suture applied); second case was a referred case after delivery she had atonic PPH managed with uterotonics and was not responding hence was referred to our hospital ; condom tamponade was administered to her and she had shock index of 1.1 and bleeding was persisting despite condom application ; after stabilizing general condition she undergone surgical intervention to stop the ongoing bleeding; subtotal hysterectomy was performed.

$\mathrm{PPH}$ a major composite of obstetric haemorrhage is ubiquitous as it can kill even healthy women within $2 \mathrm{hr}$, if unattended. World Health Organization, the International Federation of Gynecology and Obstetrics, and the Royal College of Obstetricians and Gynaecologists all recommend a uterine balloon tamponade (UBT) if uterotonics and uterine massage fail to control bleeding.${ }^{10}$ Rathod et al used Foley's catheter for tamponade and reported a success rate of $94 \% .{ }^{11}$

In $93.6 \%$ cases bleeding got controlled within $15-30$ mins of condom tamponade insertion, the balloon was inflated for an average of 18 hours before removal. Studies by Parpillewar $\mathrm{MB}$, et al quote results and duration of balloon tamponade in their studies was an average of 26 hours. ${ }^{6}$

The intrauterine balloon is considered to act by exerting "inward-to-outward pressure, ${ }^{12}$ that is greater than the systemic arterial pressure to prevent continual bleeding. The presumed mechanism of action of the tamponade in stopping the bleeding is by creating an intrauterine pressure which exerts hydrostatic pressure on the capillaries and veins in the uterus. The pressure does not necessarily have to be higher than the systemic arterial pressure. ${ }^{13}{ }^{14}$ In addition, hydrostatic pressure effect of the balloon on the uterine arteries has been proposed and stimulation of uterine contractions by the balloon in the cervix has also been demonstrated. ${ }^{15,16}$ Marcovici I et al, also found high efficacy of intrauterine inflated Foley's catheter balloon for tamponade. They reported one case of profuse hemorrhage following evacuation of 17 week fetus, controlled with intrauterine balloon tamponade. ${ }^{17}$ Time counts in the management of PPH. Most PPHs occur without any risk factor and in the absence of effective medical intervention patients with PPH on the average die within 2 hours. It is therefore imperative for every skilled birth attendant to be able to proceed to a second line of treatment such as putting in a condom tamponade when medical treatment fails.

\section{Conclusion}

Our study concludes that balloon tamponade is an effective means of controlling atonic $\mathrm{PPH}$ unresponsive to uterotonics with success rates of $96.8 \%$. At times when PPH do not respond to pharmacologic measures, Foley's intrauterine tamponade would be an emergency life saving procedure, especially in low-resource settings. As this technology avoids the need for further interventions including invasive surgical procedures like hysterectomy, it 
The New Indian Journal of OBGYN. 2021 (January-June);7(2)

reduces the hospital stay and recovery period and hence it proves to be cost effective. To conclude condom tamponade is cheap, safe, easily available, needs less expertise, life saving, less time consuming and effective if intervened in time. Especially in low resource settings can be used to control ongoing bleeding at times of referral.

\section{Acknowledgments}

Authors would like to thank Dr Thomas Burke Chief, division of Global Health and Human Rights, Emergency department MGH, Boston for providing UBT and all the departmental consultants, nursing staff and junior residents for maintaining the records and data which helped in the study.

\section{Conflict of interest: None. Disclaimer: Nil.}

\section{References}

1. Lalonde A, Daviss BA, Acosta A, Herschderfer K. Postpartum haemorrhage today: ICM/FIGO initiative. Int J Gynaecol Obstet. 2006; 94: 243-53.

2. Calvert C, Thomas SL, Ronsmans C, Wagner KS, Adler AJ, Filippi V. Identifying regional variation in the prevalence of postpartum haemorrhage: a systematic review and meta-analysis. PLoS One. 2012; 7(7): e41114

3. John S, Seang LT, Chervenak F (Eds). Postpartum uterine atony. Progress in Obstetrics and Gynaecology. 17th edition. UK: Churchill Livingstone; 2007. pp. 26474.

4. Amy JJ. Severe postpartum hemorrhage: a rational approach. Nat Med J India. 1998;11(2):86-8.

5. Santhanam R, Viswanathan RM, Priya V. Condom tamponade in the management of atonic postpartum hemorrhage .Int J Reprod Contracept Obstet Gynecol. 2018; 7(6): 2276-82

6. Parpillewar MB, Fusey SS. Intrauterine condom catheter tamponade in the management of atonic postpartum haemorrhage: a case series from a tertiary care centre in Central India .Int J Reprod Contracept Obstet Gynecol. 2017;6(8):3468-72

7. Maya ET, Buntugu KA, Ako L, Srofenyoh EK. Condom Tamponade in the Management of Primary Postpartum Haemorrhage: A Report of three cases in Ghana. African Journal of Reproductive Health. 2015;19(3):151-7.

8. Goldrath $\mathrm{MH}$. Uterine tamponade for the control of acute uterine bleeding. American Journal of Obstetrics and Gynecology. 1983;147: 869-72.
9. Akther S, Begum MR, Kabir Z, Rashid M, Laila TR, Zabeen F. Use of a condom to control massive postpartum hemorrhage. Medscape General Medicine. 2003; 5(3): 38

10. Lalonde A, International Federation of Gynecology and Obstetrics. Prevention and treatment of postpartum hemorrhage in low-resource settings. Int J Gynecol Obstet. 2012;117(2):108 -18.

11. Rathore AM, Gupta S, Manaktala U, Gupta S, Dubey C, Khan M. Uterine tamponade using condom tamponade in non-traumatic postpartum haemorrhage. J Obstet Gynecol Res. 2012; 38(9): 1162-7.

12. Ishii T, Sawada K, Koyama S, Isobe A, Wakabayashi A, Takiuchi $\mathrm{T}$, et al. Balloon tamponade during cesarean section is useful for severe post-partum hemorrhage due to placenta previa. Journal of Obstetrics and Gynecology Research. 2012; 38: 2-7.

13. 13. Georgiou C. Balloon tamponade in the management of postpartum haemorrhage: a review. BJOG. 2009;116: 748-57.

14. Sinha SM. The "tamponade test" in the management of massive postpartum hemorrhage. Obstet Gynecol. 2003;102: 641.

15. Cho Y, Rizvi C, Uppal T, Condous G. Ultrasonographic visualization of balloon placement for uterine tamponade in massive primary postpartum hemorrhage. Ultrasound Obstet Gynecol. 2008; 32: 711-3.

16. Yorifuji T, Tanaka T, Makino S, Koshiishi T, Sugimura $\mathrm{M}$, Takeda S. Balloon tamponade in atonic bleeding induces uterine contraction: attempt to quantify uterine stiffness using acoustic radiation force impulse elastography before and after balloon tamponade. Acta Obstet Gynecol Scand. 2011; 90:1171-2.

17. Marcovici I, Scoccia B. Post partum hemorrhage and intra uterine balloon tamponade. J Reprod Med. 1999; 44: 122-6.

\footnotetext{
Rupali A Gaikwad ${ }^{1}$, Shrinivas N Gadappa ${ }^{2}$

${ }^{1}$ Assistant Professor, Department of Obstetrics and Gynecology, Government Medical College, Aurangabad, Maharashtra, India; ${ }^{2}$ Professor \& Head of Department, Department of Obstetrics and Gynecology, Government Medical College, Aurangabad, Maharashtra, India.
} 